\title{
A Natureza da Sociedade Anônima e a Questão da Derrogabilidade das Regras Legais de Quorum nas Assembléias Gerais e Reuniões do Conselho de Administração.
}

\author{
Fábio Konder Comparato \\ Professor Titular de Direito Comercial na Fa- \\ culdade de Direito da Universidade de São Paulo.
}

\section{Companhias Abertas e Fechadas.}

1. Uma das tendências mais marcantes do moderno direito das sociedades anônimas consiste na superação da antiga regulação uniforme, com o estabelecimento de regimes diferentes para as companhias, conforme haja ou não ingresso no mercado de capitais.

0 direito inglês foi pioneiro, nessa matéria, com a distinção tradicional entre public e private companies. Analogamente, embora de modo menos preciso, nos Estados Unidos, extrema-se a close corporation publicly-held. $\mathrm{Na} H o l a n d a$, criou-se em 1971 a Besloten Venootschap ( $B . V$.), equivalente à private company britânica; ao lado da Naamloze Venootschap (N.V.), de há muito existente, análoga às public companies. Ademais, o legislador batavo estabeleceu outra distinção importante, entre a macro-companhia e a micro-companhia, tanto $\mathbf{B}$. V. quanto N. V., agora em função do montante do patrimônio líquido e do número de empregados. Na França, a lei de 24 de julho de 1966 sobre as sociedades mercantis consagrou a distinção entre as sociedades anônimas faisant publiquement appel à l'épargne e as que não recorrem ao mercado de capitais. $\mathrm{Na}$ Itália, a lei n. ${ }^{\circ} 216$, de 7 de junho de 1974, ao criar a CONSOB (Comissão Nacional para as Sociedades e a Bolsa), estabeleceu uma série de regras específicas para o funcionamento das sociedades com ações cotadas na Bolsa.

Se a mesma discriminação não aparece em outros países de capitalismo avançado, com a Alemanha Federal, é porque, 
lá, o desenvolvimento da sociedade por quotas de responsabilidade limitada atende, plenamente, às necessidades práticas a serem satisfeitas com a criação de companhias fechadas.

2. Essa tendência a distinguir, no modelo legal, tipos diversos de empresas, era totalmente estranha ao direito brasileiro anterior. Como escrevemos alhures ${ }^{1}$ o Decreto-lei n. ${ }^{\circ} 2.627$ fundava-se, inteiramente, num modelo ideal de companhia média, com um número nem muito reduzido nem excessivamente grande de acionistas, todos interessados no objeto de sua exploração, e decidindo, efetivamente, os destinos da companhia em assembléia, mormente pela designação dos que, na qualidade de delegados da maioria, asseguram a gestão ordinária dos negócios sociais. Inútil repetir que esse modelo era o fantasma de que falava JHERING ${ }^{2}$.

Já a atual lei de sociedades por ações perfilhou a nova orientação do direito acionário. A distinção entre companhias abertas e fechadas é estabelecida logo no capítulo I, acerca das "características e natureza da companhia ou sociedade anônima" (art. $4^{\circ}$ ), desdobrando-se em nada menos que 21 (vinte e uma) séries de disposições específicas, prevendo:

a) a criação de classes de ações (arts. $15, \S 1 .^{\circ}$ e 16) ;

b) o estabelecimento das formas das ações e sua conversibilidade (art. 22, § único) ;

c) a realização mínima das ações subscritas para a sua negociabilidade (art. 29);

d) restrições à circulação das ações (art. 36) ;

e) a suspensão dos serviços de certificados (art. 37);

f) a possibilidade de aumento estatutário de quorum deliberativo na assembléia geral (art. 129, § 1. ${ }^{\circ}$ );

g) a redução do quorum deliberativo na assembléia geral extraordinária que seja convocada para decidir qualquer das matérias previstas no art. 136 ( $\left.\$ 2 .^{\circ}\right)$;

h) a obrigatoriedade de existência de um conselho de administração (art. 138, § $2 .^{\circ}$ );

1. cf. $O$ Poder de Controle na Sociedade Anônima, 2." ed., S. Paulo, p. 387.

2. “O direito existe para realizar-se. 0 que não existe senão nas leis é um fantasma. Em compensação, o que se realiza como direito, ainda que inexistente nas leis, e mesmo que nem o povo nem a ciência o conheçam, especialmente, é direito. A realização objetiva do direito na vida, a energia com que o proclamado como necessário se executa, é o que dá ao direito seu verdadeiro valor" (El Espíritu del Derecho Romano, cit,, p. 234). 
i) o dever de sigilo do administrador, de modo a não influir na cotação dos valores mobiliários emitidos pela companhia, assim como a vedação das práticas de insider trading (art. $155, \S 10^{\circ}$ );

j) o dever de informação dos administradores (art. 157);

k) restrições à responsabilidade de administradores (art. 158, § $3 .^{\circ}$ );

1) o destino das sobras de ações, no aumento de capital mediante subscrição (art. 171 , §§ $7 .^{\circ}$ e $8^{\circ}$ ) ;

m) a exclusão do direito de preferência do acionista na subscrição de novas ações (art. 172);

n) a distribuição de dividendo inferior ao obrigatório, ou a retenção de todo o lucro do exercício (art. 202, $\left.\S 3 .^{\circ}\right)$;

o) demonstrações financeiras consolidadas (art. 249) ;

p) a alienação de controle (arts. 254 e 255) ;

q) a aquisição de controle de outra sociedade (art. 256) ;

r) a oferta pública de aquisição de controle (arts. 257 e segs.) ;

s) a redução, pela Comissão de Valores Mobiliários, mediante fixação de escala em função do capital social, de diversas percentagens mínimas de legiti. mação para a prática de atos (art. 291) ;

t) o regime especial de supressão de publicações e de pagamento de participações no lucro aos administradores (art. 294).

3. Essa longa lista de disposições específicas às companhias abertas ou fechadas parece demonstrar que se instaurou, em tal matéria, uma verdadeira distinção de natureza entre esses dois tipos de sociedades anônimas. Num deles, predomina o caráter institucional, marcado por disposições de ordem pública, não derrogáveis por deliberação dos acionistas, porque tendentes a proteger o interesse coletivo de investidores no mercado de capitais. No outro, prevalece o aspecto contratual, conferindo-se ampla liberdade de estipulação às partes para regular o funcionamento do mecanismo societário, de acordo com os seus interesses particulares.

De acordo com a tradição do sistema jurídico, o direito acionário será mais fortemente influenciado pelo modelo da 
companhia aberta ou da fechada. É o que teve ocasião de ressaltar GOWER, comparando o direito norte-americano ao inglês, nessa matéria ${ }^{3}$. Compete ao intérprete, diante de um caso concreto, saber adaptar a sua análise ao tipo de sociedade anônima em questão, procurando sobretudo evitar a aplicação do modelo institucional à companhia fechada, ou do esquema convencional à sociedade que recorre ao mercado de capitais.

Igualmente nessa perspectiva, o "fechamento" de uma companhia pode se revelar perigosa técnica de abuso de poder do controle, com a opressão dos minoritários, que vêem seu status socii substancialmente modificado ${ }^{4}$. Corrigindo lamentável omissão de nossa legislação nesse particular, a Comissão de Valores Mobiliários baixou uma Instrução, regulando o procedimento de transformação de uma companhia aberta em fechada.

4. Bem se vê, portanto, que a velha classificação das sociedades mercantis em sociedades de capitais e de pessoas, que já fora, aliás, criticada por VIVANTE ${ }^{5}$, aparece agora subvertida; ou melhor, a clivagem entre as espécies passa no interior do próprio direito acionário. Se ainda é aceitável classificar a companhia aberta na categoria das sociedades de capitais, pelo seu caráter marcadamente institucional, a companhia fechada já apresenta todas as características de uma sociedade de pessoas, animada por uma affectio societatis que

3. The constitution of the English business corporation is still regarded as essentially contractual. Whereas the American statutes tend to lay down mandatory rules, the British Companies Act relies far more on the technique of the Partnership Act, providing a standard form which applies only in the absence of contrary agreement by the parties. Much that in America is mandatory is in Britain included only in the optional model constitution the famous table A. And this constitution, or whatever the parties substitute for it, is expressly declared by the act to bind the company and the members as if it were a contract under seal. In particular this contractual constitution deals with the method of appointing the directors, with the division of powers between them and the stockholders, and, subject to important exceptions, with the meetings and votes of each. In America these matters have generally been fixed by statute, and fixed in a way which shows that the draftsmen envisaged their application to publicly owned corporations. It is unnecessary to detail the difficulties which these 'statutory norms' have caused to those wishing to provide added safeguards perfectly reasonable in the case of close corporations. (Some Contrasts between British and American Corporation Law, 69 Harvard Law Review, 1956, p. 1.376/77).

4. cf. F. HODGE NEAL, "Squeeze-Outs" of Minority Shareholders. Expulsion or Oppression of Business Associates, 1975, § 5.32 .

5. Trattato di Diritto Commerciale, 5..$^{\mathrm{a}}$ ed., II, n..$^{\circ} 352$. 
se funda no intuitus personae. Ao contrário da simples consideração dos capitais, na companhia fechada prepondera, tanto entre acionistas quanto perante terceiros, a confiança e a consideração pessoal.

Daí porque a famosa imagem de RIPERT do "maquinismo jurídico", cujo funcionamento se automatiza após o primeiro impulso do homem ${ }^{6}$, só encontra hoje aplicação para as companhias abertas. Estas, sim, são as verdadeiras sociedades "anônimas", a reunião de "posições acionárias" com a fungibilidade da pessoa dos acionistas. Nas companhias fechadas, diferentemente, por detrás das ações emerge sempre a figura dos sócios.

5.Se a distinção entre companhias abertas e fechadas não é, portanto, apenas de forma mas de fundo, importa ao intérprete discernir, cuidadosamente, a diversa natureza dos instrumentos ou atos constitutivos de uma e de outra.

Assim é que, nas companhias abertas, os estatutos se apresentam, incontestavelmente, como um ato-regra (para retomarmos a expressão consagrada dos institucionalistas franceses), com as características de um direito objetivo ou ius positum no âmbito corporativo. Já nas companhias fechadas, dificilmente se poderão desligar as regras estatutárias do acordo de vontades entre os acionistas, que lhes serviu de fundamento e inspiração. Por isso mesmo, enquanto na comparhia aberta a latitude de criação normativa dos estatutos é estreitamente limitada, preponderando sempre o ditado legal, nas companhias fechadas a fronteira entre estatutos e acordo de acionistas se esbate consideravelmente. O acordo estatutário aparece, aqui, muito mais como negócio jurídico privado, entre partes determinadas, do que como regulamento objetivo e impessoal.

A jurisprudência norte-americana já teve ocasião de firmar essa separação de princípios, em matéria de joint venture corporations. Nos Estados Unidos, como informa NoRMaN D. LATTIN ${ }^{7}$, a utilização da forma corporation para a criação de uma joint venture é velha de pelo menos um século. No entanto, os tribunais viam com reservas essa associação, com o espírito de uma partnership e a forma de uma sociedade de capitais. No caso mais recente, porém, Jacksonville Terminal

\footnotetext{
e segs.

6. cf. Aspects Juridiques du Capitalisme Moderne, 2. ${ }^{\mathrm{a}}$ ed., 1951, p. 109

7. The Law of Corporations, $2 .^{\mathbf{a}}$ ed., 1971, p. 11.
} 
Co. v. Florida East Coast Railway Co., julgado em 1966, não só foi reconhecida a validade de uma sociedade desse tipo, como o tribunal decidiu interpretar o seu funcionamento à luz do acordo de vontades inicial, e não conforme às normas objetivas de funcionamento de uma corporation. Tratava-se de cinco companhias ferroviárias, associadas na exploração de uma estação terminal. De acordo com os estatutos, qualquer acionista podia pedir a destituição do presidente da companhia, do diretor geral ou de qualquer outro administrador eleito pelo board of directors. Segundo a regra geral da lei, somente o board teria poderes para destituir esses officers. Quando acionistas, detentores de $50 \%$ do capital social, pediram a destituição do diretor presidente e de outro administrador, os demais acionistas se opuseram e recorreram ao Judiciário. O tribunal admitiu a validade da cláusula estatutária em causa e justificou o pedido de destituição, argumentando: that the discharge came about through the action of one, or a minority, rather than a majority relates, to internal management by the owners thereof under the scheme adopted by them. Ou seja, como salientou LATTIN, as estipulações constantes de um acordo de joint venture não são absorvidas pelas normas próprias de funcionamento de uma corporation.

\section{Interpretação das Regras Legais Sobre Quorum Deliberativo.}

6. É à luz desses princípios que se deve, a nosso ver, resolver in concreto as questões específicas de quorum de instalação ou de deliberação, no seio dos órgãos componentes de uma sociedade anônima.

Nas companhias abertas, que têm vocação para acolher um número ilimitado de acionistas, o quorum representa medida de proteção da maioria contra as manobras de entravamento da ação social por grupos minoritários. Imagine-se, por exemplo, uma American Telephone and Telegraph Co., com centenas de milhares de acionistas, estabelecendo um quorum de três quartos ou de quatro quintos para a deliberação em assembléia geral.

Bem ao contrário, nas companhias fechadas, em que deve prevalecer a confiança e a consideração pessoal recíprocas dos sócios, de acordo com o espírito do negócio, as regras de quorum são estabelecidas no interese da minoria, a fim de prevenir eventual abuso de poder pelos detentores do controle. 
A Lei $n .^{\circ} 6.404$, de 1976 , corrigindo a rigidez do direito anterior ${ }^{8}$, veio atender a essa necessária duplicidade de regimes. Assim, no art. 129, $\S 10^{\circ}$ admitiu que o "estatuto da companhia fechada pode aumentar o quorum exigido para certas deliberações, desde que especifique as matérias". No art. 136, estatuiu como necessária a aprovação de acionistas que representem metade, no mínimo, das ações com direito de voto, se maior quorum não for exigido pelo estatuto da companhia fechada, para a deliberação sobre as matérias aí indicadas. Em sentido oposto, no $\S 20^{\circ}$ desse mesmo artigo 136 , deferiu à Comissão de Valores Mobiliários o poder de autorizar a redução do quorum qualificado, "no caso de companhia aberta com a propriedade das ações dispersas no mercado, e cujas 3 (três) últimas assembléias tenham sido realizadas com a presença de acionistas representando menos da metade das ações com direito a voto".

7. Mas - pergunta-se - no regime da nova lei de sociedades por ações, é lícito estabelecer no estatuto a regra da unanimidade para certas e determinadas deliberações da assembléia geral ou do conselho de administração?

Entendemos que sim, obviamente em se tratando de companhia fechada.

Convém, antes de mais nada, assinalar uma circunstância ligada à elaboração da lei, e que nos parece bem significativa. O primeiro anteprojeto de lei, de autoria de BulHões PEDREIRA e LAMY FilHo, submetido para exame a um grupo de juristas em janeiro de 1975, apresentava a mesma regra do art. 129, $\S 10^{\circ}$ do texto atual, mas com o acréscimo: “... desde que especifique as matérias e não exija unanimidade". Essa parte final desapareceu, já no anteprojeto entregue ao Ministro da Fazenda. Tal fato reforça a tese de que, pela simples análise do texto atual, não se pode dizer que esteja proibida a estipulação de unanimidade nas deliberações da assembléia geral.

Todavia, muito mais do que a simples análise isolada de um texto, é a própria consideração do sistema legal que parece

8. No regime do Decreto-lei $\mathrm{n} 0^{0} 2.627$, a doutrina estimava ilegal a exacerbação estatutária do quorum legal. (cf. Miranda Valverde, Sociedades

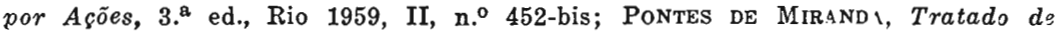
Direito Privado, t. L, § 5.322, 3; Cunha PeIxoto, Comentários à Lei d? Sociedades por A̧ø̃es, v. 3, n. ${ }^{\circ}$ 725; Souza Campos Batalha, Sociedades por Ações e Mercado de Capitais, II, p. 548/549; RUy CarneIro Guimaräes, Sociedade por Açoes, Rio, Rev. Forense, 1960, II, n. ${ }^{\circ}$ 721). Em sentido favorável, invocando justamente os princípios contratuais, FERNANDo RUDGe LEITE, Revista dos Tribunais, $440 / 58$. 
confortar a interpretação da licitude de uma exigência de votação unânime, em certas e determinadas deliberações.

Com efeito, tratando-se de companhias fechadas, em que prevalece o aspecto contratual da regulação societária, as regras de quorum, como assinalado, visam precipuamente à proteção da minoria. A exploração empresarial, aí, organizada sob a forma de sociedade anônima, atende sempre à manutenção de determinadas circunstâncias consideradas como fundamentos do negócio, como se diz na dogmática alemã (Geschäftsgrundlagen ) ${ }^{9}$. Trata-se de circunstâncias que as partes aceitaram, efetivamente, como razão determinante ou sob forma de condição (Código Civil brasileiro, art. 90). Assim, por exemplo, o fato de a organização administrativa da companhia comportar sempre a representação de todos os grupos acionários que a compõem; o de que os aumentos de capital por subscrição sejam sempre aprovados por todos eles; o de que não haja alteração do objeto social sem essa autorização unânime, etc.

Por outro lado, nas companhias fechadas, essa unanimidade deliberativa precisa ser entendida em termos pessoais e não acionários, justamente porque tais companhias não são autênticas sociedades de capitais. Dizer-se que o sistema legal proibe a obrigatoriedade de votação unânime, porque não aceita 0 direito de veto, é desconhecer que, tal seja a composição acionária, qualquer percentagem de maioria pode significar, de fato, a unanimidade. Imagine-se, por exemplo, uma companhia com duas únicas acionistas pessoas jurídicas, detentoras cada qual de 50\% do capital votante (a "filial comum" da prática européia). Aqui, a própria regra geral da maioria absoluta do art. 129 implica, in concreto, a votação unânime; e isto não apenas para certas e determinadas deliberações, como se prevê no parágrafo $1 .^{\circ}$ desse mesmo artigo, mas para todas elas, sem exceção. Da mesma forma, se se tratar de três grupos acioná-

9. E sabido que a noção românica da causa bipartiu-se, no Código Civil alemão, em fundamento (Grund) e finalidade (Zweck) do negócio. A teoria das bases ou fundamentos negociais liga-se à primeira dessas noções, e foi desenvolvida logo após a primeira guerra mundial, em conseqüência da formidável crise financeira da República de Weimar, provocando vertiginosa desvalorização do marco (cf. P. OERTMANN, Die Geschäftsgrundlage, Lípcia, 1921; KARL LARENZ, Geschäftsgrundlage und Vertragserfüllung, com tradução espanhola Base del Negocio Juridico Y Cumplimiento de los Contratos, Madri, 1956; idem, Allegemeiner Teil des deutschen Bürgerlichenrechts, Munique, 1967, p. 394 e segs. 
rios, cada qual com um terço do capital votante, se o quorum deliberativo for fixado em $70 \%$.

Se o sistema legal não repele, pois, a hipótese fática da unanimidade, por que haveria de rejeitar a tese?

8. A experiência de alguns sistemas jurídicos estrangeiros é, aliás, probante, nesse particular.

A rigor, nenhuma legislação exclui, expressamente, a imposição do voto unânime, na assembléia geral de acionistas. Onde essa exclusão se impôs, foi por mera interpretação doutrinária ou jurisprudencial.

Assim, por exemplo, na Argentina, escreve IsAAC HALPERIN, que "a lei de sociedades faculta aumentar o quorum e a maioria requeridas (arts. $243, \S 3 .^{\circ}$ e $244, \S \S 10^{\circ}$ e $2 .^{\circ}$ ), mas não poderia exigir-se a unanimidade, porque a regulação deve inspirar-se nos fins perseguidos pela lei, por isso que não se trata de uma faculdade absoluta; consagrar-se-ia o direito de veto, em contraste com o princípio majoritário, essencial no regime legal" ${ }^{10}$. O caráter absoluto da regra majoritária é, porventura, um dos "fins perseguidos pela lei"? E elemento "essencial no regime legal"? O autor, aí, avança postulados, não desenvolve argumentações.

Na Itália, limitando-se o Código Civil, no art. 2368, a declarar que a assembléia ordinária "delibera por maioria absoluta, salvo se os estatutos exigirem maioria mais elevada", a jurisprudência inclinou-se no sentido da nulidade das cláusulas de votação unânime, pois "maioria" seria conceito antitético a "unanimidade" 11. Já a doutrina dividiu-se, fundamente, sobre a questão de saber se o quorum legal seria derrogável ${ }^{12}$.

10. Sociedades Anónimas. Examen crítico del Decreto-ley 19.550, Buenos Aires, p. 599.

11. São os termos de uma massima do Tribunal de Milão, cf. Rivista delle Società, 1976 , f. $1 .^{\circ} / 2 .^{\circ}$, p. 335 .

12. A favor da validade de uma cláusula estatutária desse tipo, Ferrara Jr., Gli Imprenditori e le Società, Milão, 1971, p. 439, nota 27; Grulani, Ancora sulla derogabilità della maggioranza di legge nelle assemblee ordinarie delle Società azionarie e sui limiti di competenza dell'A.G. in sede onoraria, Riv. Notar. 1967, p. 711; ASQUINI, Sulla maggioranza richiesta per le deliberazioni della assemblea ordinaria delle società per azioni in seconda convocazione, Rivista del Diritto Commerciale, 1965, II, p. 99; Trimarchi, Invalidità delle deliberazioni di assemblea di società per azioni, Milão, 1958, p. 81, nota 13.

Contra, FerRI, Le Società, Turim, 1971, p. 422; Romano-Pavoni, Le Deliberazioni delle Asscmblee delle Società, Milão, 1951, p. 188; Graziani, Diritto delle Società, Nápoles, 5. ${ }^{\mathrm{a}}$ ed., p. 333. 
$\mathrm{Na}$ Suíça, diante da norma do art. 703 do Código federal das obrigações ( $S i$ la loi ou les statuts n'en disposent pas autrement, l'assemblée générale prend ses décisions et procède aux élections à la majorité absolue des voix attribuées aux actions représentées), doutrina e jurisprudência acabaram admitindo a perfeita validade das cláusulas estatutárias de unanimidade nas deliberações da assembléia geral ${ }^{13}$.

Nos Estados Unidos, em que o modelo legal da corporation foi, tradicionalmente, o da companhia aberta, como observamos (supra n. ${ }^{\circ}$ 3), chegou-se, embora mais laboriosamente, às mesmas conclusões. No precedente Benintendi $v$. Kenton Hotel, Inc., julgado pela Corte de Apelação de Nova Iorque em 1945, uma maioria de 4 a 3 julgou ilícita a estipulação de unanimidade nas deliberações da assembléia geral, sobretudo para eleições de diretores, e nas deliberações da diretoria. Admitiu, no entanto, que os estatutos só pudessem ser reformados à unanimidade. Logo após esse julgamento, a lei de sociedades por ações do Estado foi alterada de forma a facultar a introdução, na charter of incorporation, de cláusulas de votação unânime em assembléias e no board of directors.

No precedente Katcher $v$. Ohsman, julgado pelo Tribunal Superior de Nova Jérsia em 1953, a possibilidade jurídica da exigência de votação unânime foi amplamente admitida, embora como obiter dictum, pois a causa girou em torno da legalidade de uma exacerbação do quorum majoritário, por disposição dos estatutos. Em sua declaração de voto, frisando o aspecto de proteção da minoria, disse o Juiz STEIN: In the absence of contrary agreement and provision, the law presumes that stockholders intend to make the rule of the majority controlling, but I know of no valid reason why stockholders are not at liberty to establish for themselves a voting rule or formula which will protect the holder of a single share against the action of all the other shareholders becoming binding or controlling upon him.

Posteriormente a esses precedentes, o Model Business Corporation Act, seguido pela grande maioria das legislações estaduais, passou a prever, em textos de ampla incidência, a

13. cf. FRITz DE SteIGer, Le Droit des Sociétés Anonymes en Suisse, Lausanne, 1973, p. 211. 
total liberdade para a alteração estatutária do quorum legal, em deliberações da assembléia geral ${ }^{14} \mathrm{e}$ do board of directors ${ }^{15}$.

9. No que tange, especificamente, às deliberações do conselho de administração, a nossa Lei $n .^{\circ} 6.404$ parece, no entanto, comportar um obstáculo à exigência estatutária de unanimidade. Em seu art. 140, IV, prevê-se que o estatuto estabeleça "as normas sobre convocação, instalação e funcionamento do conselho, que deliberará por maioria de votos". Essa oração relativa final implicaria a proibição de se estabelecer a unanimidade para certas e determinadas deliberações?

Pensamos que não.

Ressalte-se, em primeiro lugar, que o sistema legal seria incongruente se fixasse, para o funcionamento do conselho de administração, regras de quorum mais rígidas do que na assembléia geral. Embora o conselho tenha atribuições próprias, ele se apresenta, de certo modo, como uma emanação da assembléia que, pela lei, "tem poderes para decidir todos os negócios relativos ao objeto da companhia e tomar as resoluções que julgar convenientes à sua defesa e desenvolvimento" (art. 121). A assembléia funciona, pois, como última instância societária, nada impedindo que as decisões do conselho possam ser revistas ou alteradas mediante recurso ao corpo acionário. Não faria sentido, portanto, impedir uma unanimidade no conselho e não na assembléia geral.

Atente-se, ademais, para o fato de que o conselho de administração foi concebido como órgão obrigatório apenas para as companhias abertas, as de capital autorizado e as de economia mista (arts. 138, $\S 20^{\circ}$ e 239). As companhias fechadas, que não sejam de capital autorizado nem de economia mista, poderão organizar dicotomicamente a sua administração em conselho e diretoria, mas não estão obrigadas a fazê-lo. O legislador brasileiro afastou-se, portanto, nesse capítulo, do sistema alemão, em que toda sociedade anônima comporta um

14. § 32. Quorum of shareholders (First Sentence)

Unless otherwise provided in the articles of incorporation, a majority of the shares entitled to vote, represented in person or by proxy, shall constitute a quorum at a meeting of shareholders, but in no event shall a quorum consist of less than one-third of the shares entitled to vote at the meeting.

15. $\S 40$. Quorum of Directors

A majority of the number of directors fixed by or in the manner provided in the by-laws or in the absence of a by-law fixing or providing for the number of directors, then of the number stated in the articles of incorporation, shall constitute a quorum for the transaction of business unless a greater number is required by the articles of incorporation or the by-laws. 
Aufsichtsrat e um Vorstand. A Lei n. ${ }^{\circ}$ 6.404, nessa parte, apresenta, manifestamente, um esquema normativo adequado ao funcionamento de companhias de tipo institucional - como as abertas e as de economia mista - em que a exacerbação do quorum deliberativo representaria um entrave ao funcionamento normal dos órgãos societários.

Parece-nos, portanto, que a oração relativa "que deliberará por maioria de votos", no art. 140, IV, expressa uma regra geral, sem excluir outras soluções particulares. 0 próprio estilo vago do texto, aliás, conduz a esse raciocínio, bastando compará-lo com o do art. 129 caput. Que maioria de votos? Simples ou absoluta? Computada em relação à totalidade de membros do conselho, ou dos conselheiros presentes à reunião? Deixa-se, portanto, uma boa latitude de determinação aos estatutos, mesmo em se tratando de companhia aberta. Com base em que razão jurídica, então, fixar-se uma interpretação literal da norma para as companhias fechadas?

Não vemos, pois, como recusar validade à cláusula estatutária da companhia fechada, impondo a unanimidade de votos no conselho para certas e determinadas deliberações. Ressalte-se, contudo, que esta última precisão, constante da norma do art. $129, \S 10^{\circ}$, é de rigor também no conselho de administração. A exigência de unanimidade, embora perfeitamente legítima, não se pode converter em regra geral; ela só deve ser aplicada como exceção, mediante precisa definição de hipóteses.

10. Ainda aí, o recurso ao direito comparado é importante, para demonstrar que a solução por nós esposada nada tem de aberrante, no plano dos princípios.

$\mathrm{Na}$ lei francesa sobre as sociedades mercantis, de 1966, por exemplo, dispôs-se que "a menos que os estatutos prevejam maioria mais elevada, as decisões (do conselho de administração da sociedade anônima) são tomadas pela maioria dos membros presentes" (art. 100, segunda alínea). Comentando esse dispositivo, Pierre-GIlles GoURlay ${ }^{16}$ indaga se os estatutos podem impor a unanimidade. E responde, com estas judiciosas considerações:

Une interprétation littérale du deuxième alinéa de l'article 100 de la loi de 1966 entrainerait une réponse négative, car par définition la majorité est contraire à l'unanimité. Mais nous pensons que le

16. Le Conseil d'administration de la Socitété Anonyme, Paris, 1971, p. 191. 
législateur, en employant le terme majorité, n'a pas entendu proscrire l'unanimité et que les statuts demeurent libres d'imposer cette dernière. Sur le plan pratique, il est évident que cette solution pourrait entraver le fonctionnement du conseil et paralyserait la vie sociale. On peut toutefois admettre qu'une telle unanimité soit exigée pour certaines décisions particulièrement importantes (alienation d'immeuble par exemple). On peut même concevoir que cette unanimité soit nécessaire, même en l'absence de dispositions statutaires, lorsque la décision du conseil intéresse les droits personnels des administrateurs. Ainsi notamment pour une distribution inégale des tantièmes ou des jetons de présence.

Par ailleurs, certains statuts prévoient que si une décision du conseil n'est pas adoptée à l'unanimité, les administrateurs ayant voté contre la décision peuvent en référér à l'assemblée générale qui tranche alors la question. Une telle disposition ne parait pas illégale, étant bien entendu que l'assemblée ne pourrait connaitre de problèmes qui sont de la compétence exclusive du conseil.

No direito italiano, o Código Civil estatuiu que "as deliberações do conselho de administração são tomadas por maioria absoluta, salvo diversa disposição do ato constitutivo" (art. 2.388, segunda alínea). Diante desse dispositivo, um bom número de companhias previu, em seus estatutos, um quorum deliberativo de maioria qualificada e mesmo de unanimidade dos conselheiros presentes. Há, também, casos de estatutos prevendo a possibilidade de recurso dos administradores vencidos à assembléia geral ${ }^{17}$.

Resumindo e concluindo, temos que o modelo legal da sociedade anônima tem sido usado, largamente, para regular as explorações empresariais do mais diverso tipo. A tendência mais saliente, no Direito atual, consiste em distinguir dois submodelos de companhia, conforme haja ou não recurso ao mercado de capitais. Tais submodelos podem, para efeitos práticos, ser denominados, sinteticamente, institucional e convencional.

17. Cf. Rivista delle Società, 1974, f. 3-4, p. 623/624. 
A derrogação estatutária das regras legais sobre quorum, em assembléias gerais e reuniões do conselho de administração de sociedades anônimas, é perfeitamente legítima em se tratando de companhias do tipo convencional. Essa derrogação pode, até mesmo, chegar à exigência de unanimidade em certas e determinadas deliberações. 